\title{
Synthesis, structural characterization and magnetic properties of RCrO4 oxides, R=Nd, Sm, Eu and Lu
}

\section{Document Version}

Final published version

Link to publication record in Manchester Research Explorer

\section{Citation for published version (APA):}

Jimenez-Melero, E., Isasi, J., \& Saez-Puche, R. (2000). Synthesis, structural characterization and magnetic properties of RCrO4 oxides, R=Nd, Sm, Eu and Lu. Journal of Alloys and Compounds, 312(1-2), 53-59.

\section{Published in:}

Journal of Alloys and Compounds

\section{Citing this paper}

Please note that where the full-text provided on Manchester Research Explorer is the Author Accepted Manuscript or Proof version this may differ from the final Published version. If citing, it is advised that you check and use the publisher's definitive version.

\section{General rights}

Copyright and moral rights for the publications made accessible in the Research Explorer are retained by the authors and/or other copyright owners and it is a condition of accessing publications that users recognise and abide by the legal requirements associated with these rights.

\section{Takedown policy}

If you believe that this document breaches copyright please refer to the University of Manchester's Takedown Procedures [http://man.ac.uk/04Y6Bo] or contact uml.scholarlycommunications@manchester.ac.uk providing relevant details, so we can investigate your claim.

\section{OPEN ACCESS}




\title{
Synthesis, structural characterization and magnetic properties of $\mathrm{RCrO}_{4}$ oxides, $\mathrm{R}=\mathrm{Nd}, \mathrm{Sm}, \mathrm{Eu}$ and $\mathrm{Lu}$
}

\author{
E. Jiménez, J. Isasi, R. Sáez-Puche* \\ Departamento Química Inorgánica I, Facultad de Ciencias Químicas, Universidad Complutense, 28040 Madrid, Spain
}

Received 30 May 2000; accepted 21 June 2000

\begin{abstract}
This paper reports the specific conditions used in the preparation of $\mathrm{RCrO}_{4}$ oxides, $\mathrm{R}=\mathrm{Nd}, \mathrm{Sm}, \mathrm{Eu}$ and $\mathrm{Lu}$, the structural determination, and the study of their magnetic behaviour. The structure of these compounds has been refined from X-ray powder diffraction by the Rietveld method, assigning the zircon type, space group $I 4_{1} /$ amd. A linear decrease has been observed in the lattice parameters from $\mathrm{NdCrO}_{4}$ to $\mathrm{LuCrO}_{4}$, according to the lanthanide contraction. Magnetic susceptibility measurements reveal the existence of an antiferromagnetic ordering in which both $\mathrm{Cr}^{5+}$ and $\mathrm{R}^{3+}$ sublattices are involved. In the case of $\mathrm{NdCrO}_{4}$, the estimated Néel temperature appears to be lower than $2 \mathrm{~K}$; for the remaining oxides, it is $14.9 \mathrm{~K}, 15.9 \mathrm{~K}$ and $9.9 \mathrm{~K}$ for $\mathrm{Sm}$, Eu and Lu, respectively. A superexchange mechanism has been proposed to explain such a magnetic behaviour. The pathways through which these interactions take place have also been analysed, taking into account the structural features that these oxides present. $\mathrm{The}^{\mathrm{Cr}}{ }^{5+}$ plays an important role as a promoter of these interactions in the $\mathrm{R}^{3+}$ sublattice. (C) 2000 Elsevier Science B.V. All rights reserved.
\end{abstract}

Keywords: Magnetically ordered materials; Chemical synthesis; X-ray diffraction; Exchange and superexchange; Magnetic measurements

\section{Introduction}

The $\mathrm{RXO}_{4}$ compounds, where $\mathrm{R}$ is a trivalent rare-earth ion and $\mathrm{X}$ is phosphorous, arsenic and vanadium have been intensively investigated for their attractive crystallographic, magnetic and luminescent properties [1-5]. They crystallise in two different structural types, depending on the size of both $\mathrm{R}$ and $\mathrm{X}$. The majority of the $\mathrm{RPO}_{4}$ compounds, with $\mathrm{R}=\mathrm{La}-\mathrm{Tb}$, adopts the monazite type, space group $P 2_{1} / n$, together with the first member of the vanadates, $\mathrm{LaVO}_{4}$. The remaining members of both families of compounds crystallise with the so-called zircon-type structure, showing tetragonal symmetry, space group $\mathrm{I}_{1}$ / amd.

As far as we know, few studies have been carried out concerning the $\mathrm{RCrO}_{4}$ oxides, probably due to the difficulty in preparing pure samples. In fact, single crystals have still not been obtained, because of the instability of the $\mathrm{Cr}^{5+}$ at the synthesis temperatures. In this sense, it is remarkable that these phases decompose in air at $600^{\circ} \mathrm{C}$.

$\mathrm{RCrO}_{4}$ oxides form a family of compounds that crys-

\footnotetext{
*Corresponding author. Tel.: +34-91-3944-353; fax: +34-91-3944-

E-mail address: rsp92@eucmax.sim.ucm.es (R. Sáez-Puche).
} 352. tallise with two structural types: $\mathrm{LaCrO}_{4}$ shows monazite structure [6,7], while from $\mathrm{Pr}$ to $\mathrm{Lu}$ the $\mathrm{RCrO}_{4}$ compounds crystallise with the zircon type [8]. This fact corresponds with the structural features observed in the vanadates. However, the $\mathrm{PrCrO}_{4}$ is dimorphic and adopts both structures simultaneously [9]. Attempts to isolate one of the above-mentioned phases in the $\mathrm{PrCrO}_{4}$ oxide have been unsuccessful up to now.

In this paper we report the specific conditions used in the preparation of $\mathrm{RCrO}_{4}$ oxides, $\mathrm{R}=\mathrm{Nd}, \mathrm{Sm}, \mathrm{Eu}$ and $\mathrm{Lu}$, as pure phases, and a detailed analysis of the structure is also included. All these compounds are isostructural showing the zircon-type structure [10-12], which can be described as built up by chains of edge-sharing distorted $\left(\mathrm{RO}_{8}\right)$ bisdisphenoids running parallel to the $a$-axis connected by $\mathrm{CrO}_{4}$ tetrahedra, sharing edges along the $c$-axis, as can be seen in Fig. 1(a). The $a b$ plane is shown in Fig. 1 (b), where the presence of rows $\mathrm{RO}_{8} / \mathrm{CrO}_{4}$ connected by corners, can be visualized along the $b$-axis.

\section{Experimental}

The samples were prepared by heating stoichiometric amounts of $\mathrm{R}\left(\mathrm{NO}_{3}\right)_{3} \cdot 6 \mathrm{H}_{2} \mathrm{O}$ and $\mathrm{Cr}\left(\mathrm{NO}_{3}\right)_{3} \cdot 9 \mathrm{H}_{2} \mathrm{O}$, follow- 


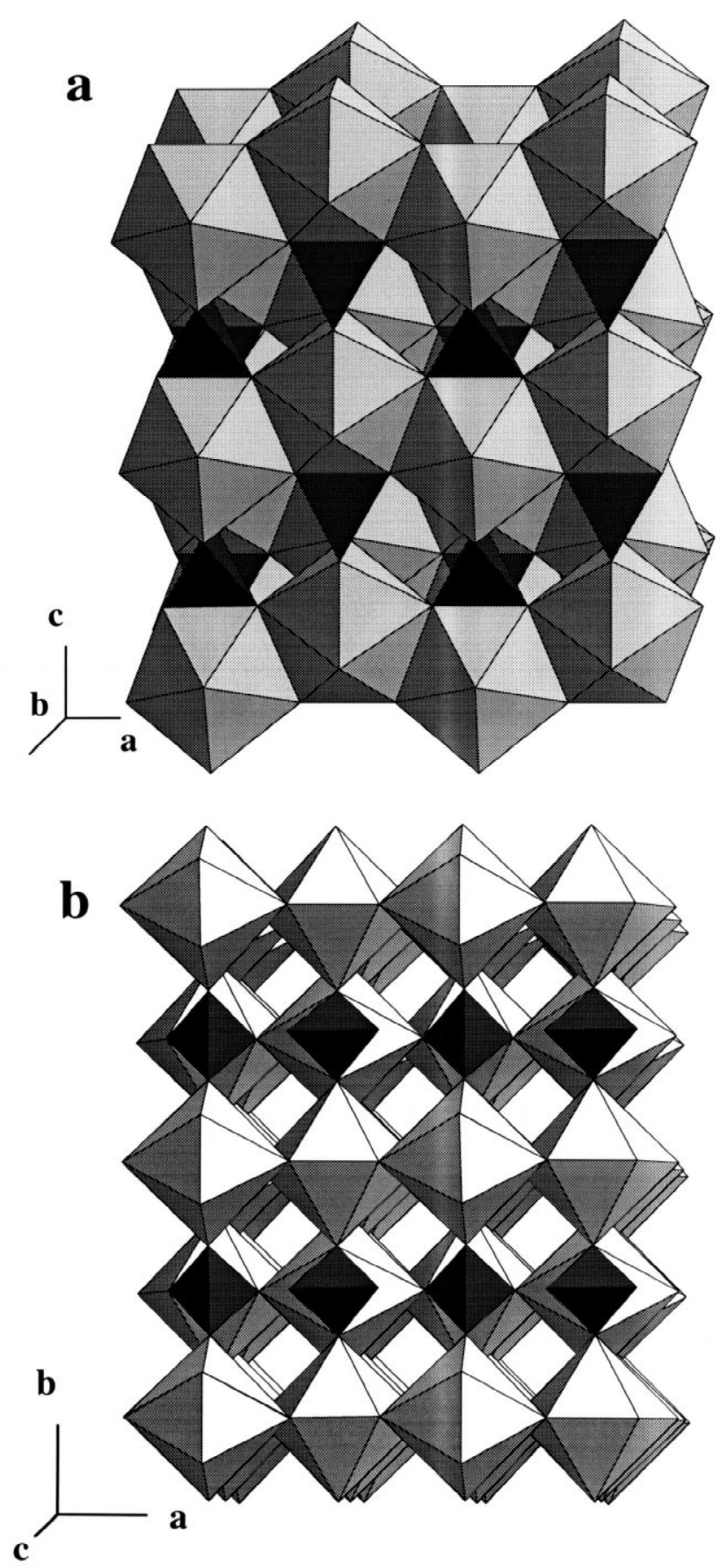

Fig. 1. (a) Perspective view of the zircon-type structure showing the chains of edge-sharing $\left(\mathrm{RO}_{8}\right)$ bisdisphenoids polyhedra along the $a$-axis connected by $\mathrm{CrO}_{4}$ tetrahedra. (b) Projection of the structure considering two chains, constituted by $\mathrm{RO}_{8}$ groups.

ing the thermal scheme: $30 \mathrm{~min}$ at $433 \mathrm{~K}, 30 \mathrm{~min}$ at $473 \mathrm{~K}$ and $60 \mathrm{~min}$ at $853 \mathrm{~K}$. An oxygen flow is used in order to stabilise the $5+$-oxidation state in the chromium. The reaction takes place according to:

$\mathrm{R}\left(\mathrm{NO}_{3}\right)_{3} \cdot 6 \mathrm{H}_{2} \mathrm{O}+\mathrm{Cr}\left(\mathrm{NO}_{3}\right)_{3} \cdot 9 \mathrm{H}_{2} \mathrm{O}=\mathrm{RCrO}_{4}+6 \mathrm{NO}_{2}$ $+15 \mathrm{H}_{2} \mathrm{O}$
The products obtained are green, and the X-ray diffraction patterns show the existence of single phases in all the cases.

Powder X-ray diffraction patterns were registered at a rate of $0.1^{\circ}(2 \theta) \mathrm{min}^{-1}$ using a Philips $\mathrm{X}^{\prime}$ Pert MPD, Ni filtered $\mathrm{CuK} \alpha$ radiation. A step scan of $0.04^{\circ}(2 \theta)$ in the range $10^{\circ}-120^{\circ}$ and a counting time of $15 \mathrm{~s}$ for each step was employed. Rietveld full-profile refinement was done using the FULLPROF program [13].

Magnetic susceptibility measurements were performed in a Quantum Design XL-SQUID magnetometer at 100 Oe between 1.7 and $300 \mathrm{~K}$. The susceptibilities were corrected for ionic diamagnetism using the values of $-20 \times 10^{-6}$ emu mol ${ }^{-1}$ for $\mathrm{R}^{3+},-12 \times 10^{-6} \mathrm{emu} \mathrm{mol}^{-1}$ for $\mathrm{O}^{2-}$ and $-5 \times 10^{-6} \mathrm{emu} \mathrm{mol}^{-1}$ for $\mathrm{Cr}^{5+}$ [14].

\section{Results and discussion}

\subsection{Structural characterization}

The structures of these oxides have been refined from X-ray powder diffraction patterns using the Rietveld method (FULLPROF program), starting from the isostructural phase $\mathrm{YVO}_{4}$ [15]. The reflection conditions are compatible with the space group $I 4_{1} /$ amd $(Z=4)$. The atoms occupy the following positions: rare earth in $4 a(0$, $3 / 4,1 / 8)$, chromium in $4 b(0,1 / 4,3 / 8)$ and oxygen in $16 h(0, y, z)$.

The final results of this refinement are presented in Table 1 (for the crystallographic parameters and the $R$ factors), and Table 2 (for the bond length distances). Figs. 2 and 3 show, as examples, the observed, calculated and difference X-ray profiles of powder diffraction for $\mathrm{Nd}$ and Eu oxides.

As can be observed in Table 1, the lattice parameters of these phases decrease linearly with the reduction of the ionic radius of the rare earth from $\mathrm{Nd}$ to $\mathrm{Lu}$, according to the lanthanide contraction. The $\mathrm{R}$ ions are centred in their respective distorted bisdisphenoids with an octa-coordination, while the coordination of $\mathrm{Cr}$ is tetrahedral (Table 2).

\subsection{Magnetic measurements}

Amongst the members of this family of compounds, $\mathrm{LuCrO}_{4}$ presents the simplest magnetic behaviour, since only the $\mathrm{Cr}^{5+}$ contribution must be considered. The temperature dependence of magnetic susceptibility for $\mathrm{LuCrO}_{4}$ is shown in Fig. 4. The susceptibility obeys a Curie-Weiss behaviour in the temperature range 40-300 K and the effective magnetic moment calculated from the slope of the straight line is $1.61 \mu_{\mathrm{B}}$. Such a value is lower than the calculated one considering the spin only contribution for $\mathrm{Cr}^{5+}$ with $S=1 / 2$, which is $1.73 \mu_{\mathrm{B}}$. This difference can be explained by taking into account the fact that the crystal field ground state of $\mathrm{Cr}^{5+}$ in tetrahedral 
Table 1

Rietveld refinement data for $\mathrm{RCrO}_{4}, \mathrm{R}=\mathrm{Nd}, \mathrm{Sm}, \mathrm{Eu}$ and $\mathrm{Lu}^{\mathrm{a}}$

\begin{tabular}{|c|c|c|c|c|c|c|c|c|}
\hline \multirow{2}{*}{$\frac{\text { Compound }}{\mathrm{R}}$} & \multicolumn{2}{|c|}{ Unit cell parameters } & \multicolumn{2}{|c|}{ Oxygen position } & \multicolumn{4}{|c|}{ Reliability factors } \\
\hline & $a(\AA)$ & $c(\AA)$ & $y$ & $z$ & $R_{\mathrm{p}}$ & $R_{\mathrm{wp}}$ & $R_{\mathrm{b}}$ & $R_{\text {exp }}$ \\
\hline $\mathrm{Nd}$ & $7.305(2)$ & $6.394(7)$ & $0.426(1)$ & $0.210(2)$ & 12.6 & 16.4 & 5.4 & 4.7 \\
\hline $\mathrm{Sm}$ & $7.244(4)$ & $6.347(7)$ & $0.429(3)$ & $0.208(1)$ & 12.3 & 15.9 & 4.8 & 5.5 \\
\hline $\mathrm{Eu}$ & $7.218(2)$ & $6.327(3)$ & $0.428(2)$ & $0.210(5)$ & 11.5 & 15.0 & 5.4 & 5.7 \\
\hline $\mathrm{Lu}$ & $7.020(4)$ & $6.193(1)$ & $0.431(5)$ & $0.219(5)$ & 13.8 & 18.4 & 6.3 & 5.4 \\
\hline
\end{tabular}

Table 2

Interatomic distances $(\AA)$ for $\mathrm{RCrO}_{4}, \mathrm{R}=\mathrm{Nd}, \mathrm{Sm}, \mathrm{Eu}$ and $\mathrm{Lu}$

\begin{tabular}{lllll}
\hline $\mathrm{R}$ & $\mathrm{Nd}$ & $\mathrm{Sm}$ & $\mathrm{Eu}$ & $\mathrm{Lu}$ \\
\hline $\mathrm{R}-\mathrm{O}$ & $2.422(5) \times 4$ & $2.382(5) \times 4$ & $2.385(1) \times 4$ & $2.310(2) \times 4$ \\
$\mathrm{R}-\mathrm{O}$ & $2.503(4) \times 4$ & $2.485(1) \times 4$ & $2.484(1) \times 4$ & $2.486(5) \times 4$ \\
$\mathrm{Cr}-\mathrm{O}$ & $1.667(1) \times 4$ & $1.673(5) \times 4$ & $1.653(3) \times 4$ & $1.597(5) \times 4$ \\
\hline
\end{tabular}

coordination is ${ }^{2} \mathrm{E}$. This term is mixed with the higherlying ${ }^{2} \mathrm{~T}$ excited state via spin-orbit coupling, giving rise to a magnetic moment that depends on both the orbit coupling constant $\lambda$ and the $10 \mathrm{Dq}$ value [16]. Since $\mathrm{Cr}^{5+}$ has just one unpaired electron and the $\lambda$ constant is positive, the experimental value of $1.61 \mu_{\mathrm{B}}$ can be fully justified. Moreover, the net maximum observed at $9.9 \mathrm{~K}$ and the negative value of the Weiss constant $\theta=-7.84 \mathrm{~K}$ (Table 3 ) is indicative of the existence of antiferromagnetic interactions in the $\mathrm{Cr}^{5+}$ sublattice.

A detailed analysis of the structure is important to establish the possible pathways through which these interactions take place. The superexchange interactions are quite complex, since the $\mathrm{CrO}_{4}$ tetrahedra are isolated from each other by the diamagnetic $\mathrm{LuO}_{8}$ bisdisphenoids. The pathways include the sequences $\mathrm{Cr}^{5+}-\mathrm{O}-\mathrm{O}-\mathrm{Cr}^{5+}$ or $\mathrm{Cr}^{5+}-\mathrm{O}-\mathrm{Lu}-\mathrm{O}-\mathrm{Cr}^{5+}$, being diamagnetic atoms involved in both cases (Fig. 5). The bond angles are very different to $180^{\circ}$ and the $\mathrm{Cr}-\mathrm{Cr}$ distance presents a value of $6.4 \AA$, yielding a poor overlap of the d-orbitals. This fact could justify the low Néel temperature estimated for $\mathrm{LuCrO}_{4}$ (9.9 K).

The variation of the magnetic susceptibility with the temperature for $\mathrm{SmCrO}_{4}$ and $\mathrm{EuCrO}_{4}$ is shown in Figs. 6 and 7 , respectively. The presence of a net maximum at 14.9 $\mathrm{K}$ and $15.9 \mathrm{~K}$ can be attributed to the existence of antiferromagnetic interactions in which both $\mathrm{R}^{3+}$ and $\mathrm{Cr}^{5+}$ sublattices are involved. The influence of the temperature on the magnetic susceptibility for these $\mathrm{RCrO}_{4}$ oxides $(\mathrm{R}=\mathrm{Sm}$ and $\mathrm{Eu})$ above $40 \mathrm{~K}$ can be explained considering the $\mathrm{Cr}^{5+}$ paramagnetic contribution and the characteristic magnetic behaviour of $\mathrm{Sm}^{3+}$ and $\mathrm{Eu}^{3+}$. It is well known that the spacing of the multiplet levels are not large compared to $k T$, which implies that not all the ions are in their ground state, so the excited states should be taken into consideration in the calculations of the magnetic

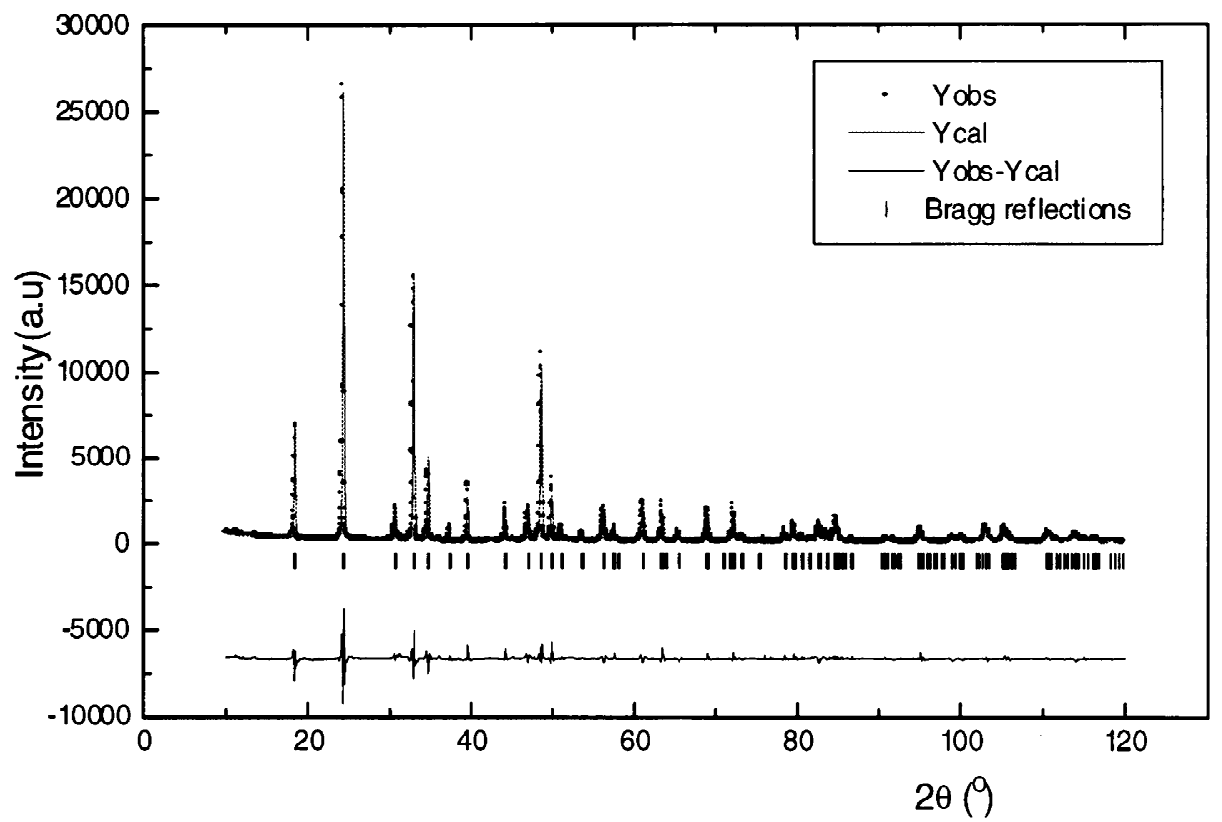

Fig. 2. X-ray diffraction pattern for $\mathrm{NdCrO}_{4}$. 


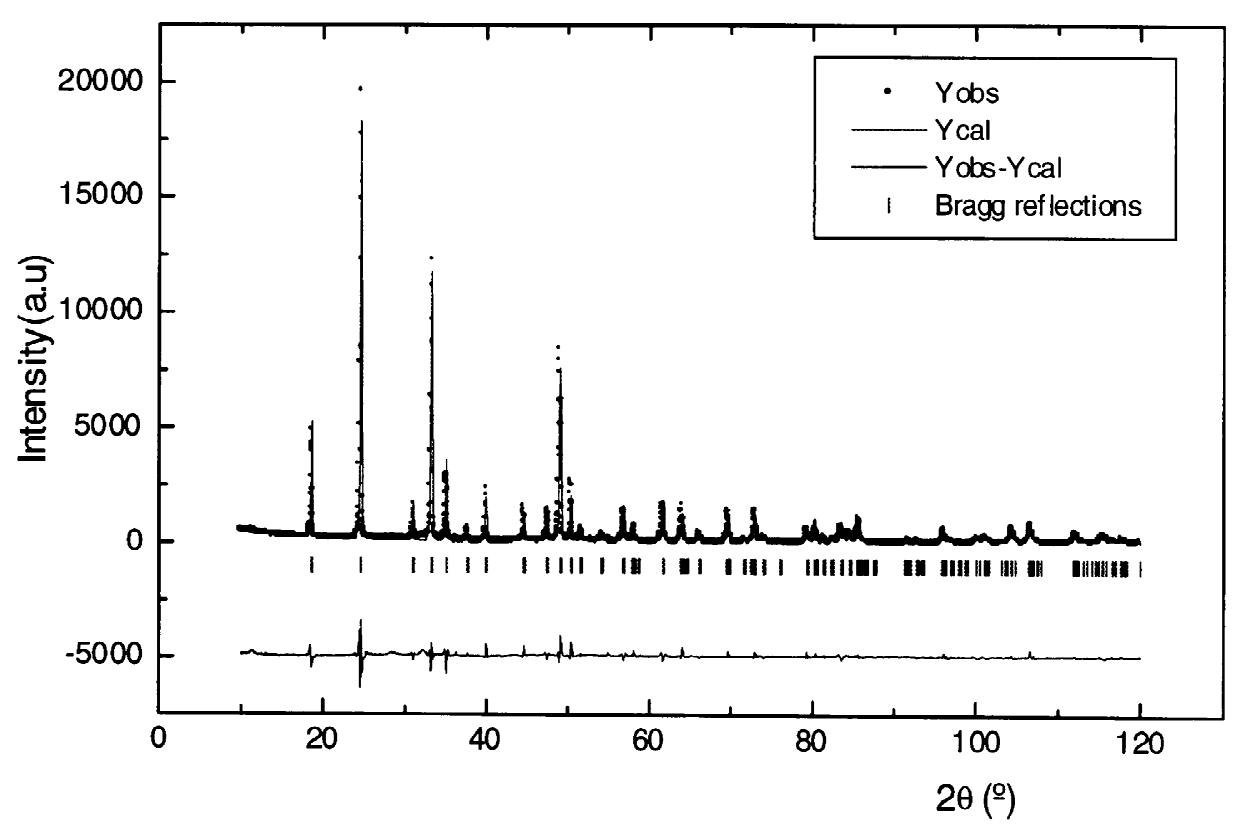

Fig. 3. X-ray diffraction pattern for $\mathrm{EuCrO}_{4}$.

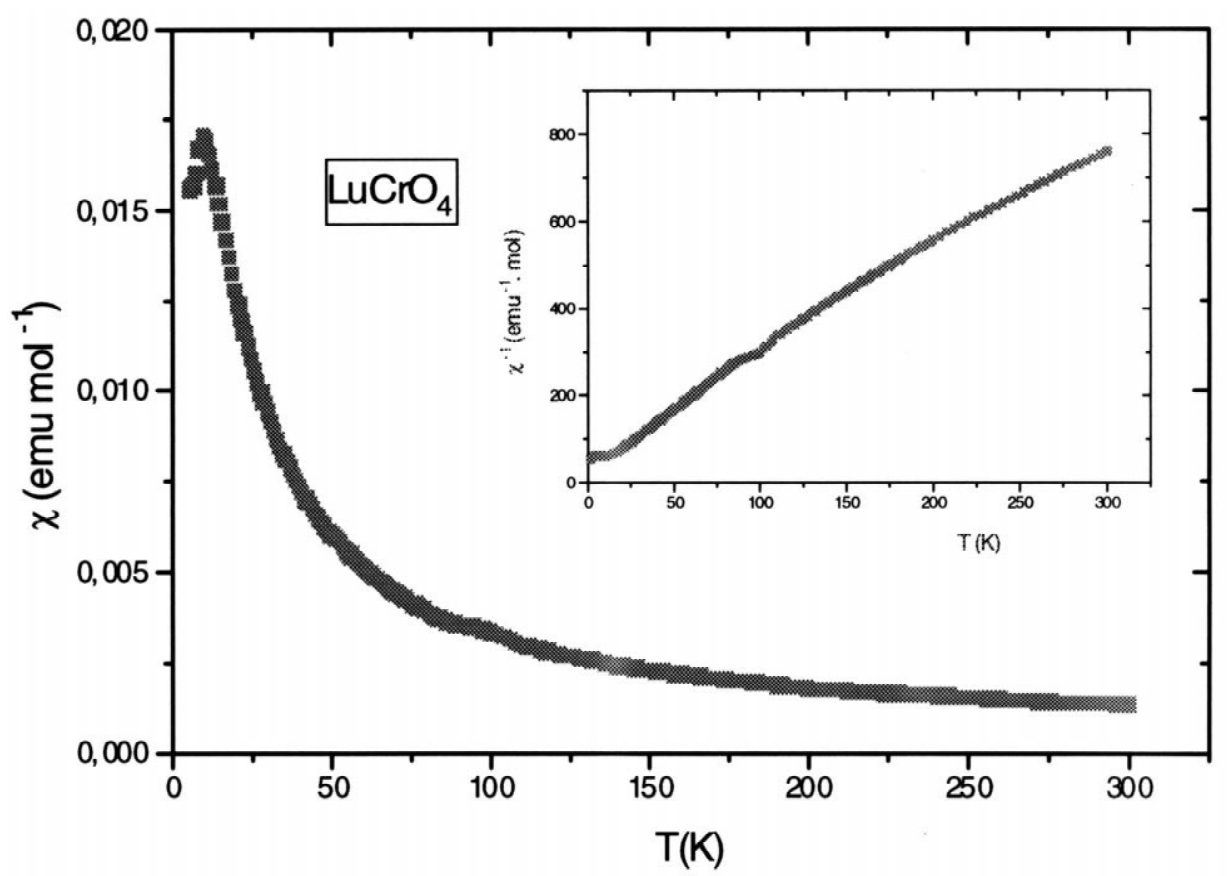

Fig. 4. Temperature dependence of the molar magnetic susceptibility for $\mathrm{LuCrO}_{4}$. The inset is the $\chi^{-1}$ vs. $T$ plot.

Table 3

Observed $\left(\mu_{0}\right)$ and theoretical $\left(\mu_{\mathrm{t}}\right)$ magnetic moments, Weiss constant $(\theta)$ and Néel temperature $\left(T_{\mathrm{N}}\right)$ for $\mathrm{RCrO}_{4}$ oxides, $\mathrm{R}=\mathrm{Nd}, \mathrm{Sm}, \mathrm{Eu}$ and $\mathrm{Lu}$

\begin{tabular}{lllll}
\hline $\mathrm{R}$ & $\mu_{0}\left(\mu_{\mathrm{B}}\right)$ & $\mu_{\mathrm{t}}\left(\mu_{\mathrm{B}}\right)$ & $T_{\mathrm{N}}(\mathrm{K})$ & $\theta(\mathrm{K})$ \\
\hline $\mathrm{Nd}$ & 4.06 & 4.02 & - & -45.5 \\
$\mathrm{Sm}$ & $2.38^{\mathrm{a}}$ & $2.36^{\mathrm{a}}$ & 14.9 & - \\
$\mathrm{Eu}$ & $3.75^{\mathrm{a}}$ & $3.89^{\mathrm{a}}$ & 15.9 & - \\
$\mathrm{Lu}$ & 1.61 & 1.59 & 9.9 & -7.84 \\
\hline
\end{tabular}

${ }^{\text {a }}$ At room temperature. susceptibility [17]. The magnetic moments obtained at room temperature agree with those calculated for these oxides, after discounting the $\mathrm{Cr}^{5+}$ contribution obtained from the $\mathrm{LuCrO}_{4}$ (Table 3).

The antiferromagnetic interactions assigned to the $\mathrm{Sm}$, $\mathrm{Eu}$ and $\mathrm{Lu}$ phases contrast with the ferromagnetic behaviour reported for the remaining isostructural zircon-type $\mathrm{RCrO}_{4}$ compounds, where $\mathrm{R}=\mathrm{Gd}-\mathrm{Yb}$ [18]. Moreover, in the case of the isostructural $\mathrm{RXO}_{4}$, where $\mathrm{X}$ is a diamagnetic cation, cooperative interactions have not been de- 


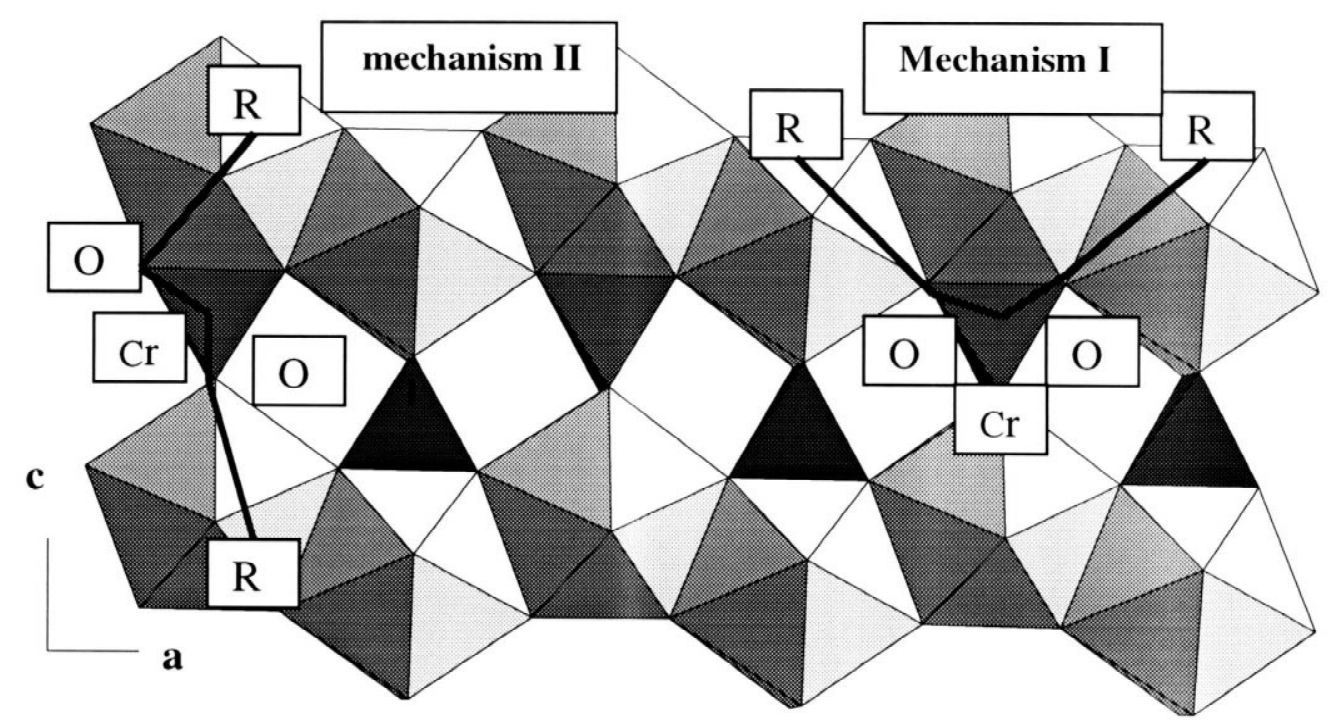

Fig. 5. Scheme of the two proposed superexchange pathways of the type $\mathrm{R}-\mathrm{O}-\mathrm{Cr}-\mathrm{O}-\mathrm{R}$ for the $\mathrm{RCrO}_{4}$ oxides.

tected in the rare earth sublattice down to $4.2 \mathrm{~K}[10,19,20]$ This fact indicates the important role that the $\mathrm{Cr}^{5+}$ plays as a promoter of the ferro- or antiferromagnetic interactions in the rare earth sublattice.

The temperature dependence of the reciprocal molar magnetic susceptibility between 2 and $300 \mathrm{~K}$ for $\mathrm{NdCrO}_{4}$ is shown in Fig. 8. The variation of the susceptibility in this oxide obeys the Curie-Weiss law from 300 to $50 \mathrm{~K}$ approximately. The downwards deviation in the $\chi^{-1}$ vs. $T$ observed below $20 \mathrm{~K}$ and the negative value of the Weiss constant (Table 3) can be ascribed to the crystal field effects. Similar results have been reported earlier for different neodymium oxides for which non-cooperative interactions are operative [19,20]. However, the small value of $\chi T$ obtained at $2 \mathrm{~K}$ (Fig. 8, inset), which is only $0.11 \mathrm{emu} \mathrm{K} \mathrm{mol}^{-1}$, indicates that antiferromagnetic interactions could be operating at these low temperatures.

Taking into account the obtained results and structural description of these compounds, it is very important to establish the mechanism through which the antiferromagnetic interactions take place. Direct $\mathrm{R}^{3+}-\mathrm{R}^{3+}$ and/or superexchange of the type $\mathrm{R}-\mathrm{O}-\mathrm{R}$ between the $\mathrm{RO}_{8}$ units, which share edges forming chains along the $a$-axis, must be considered. However, this type of interaction should be

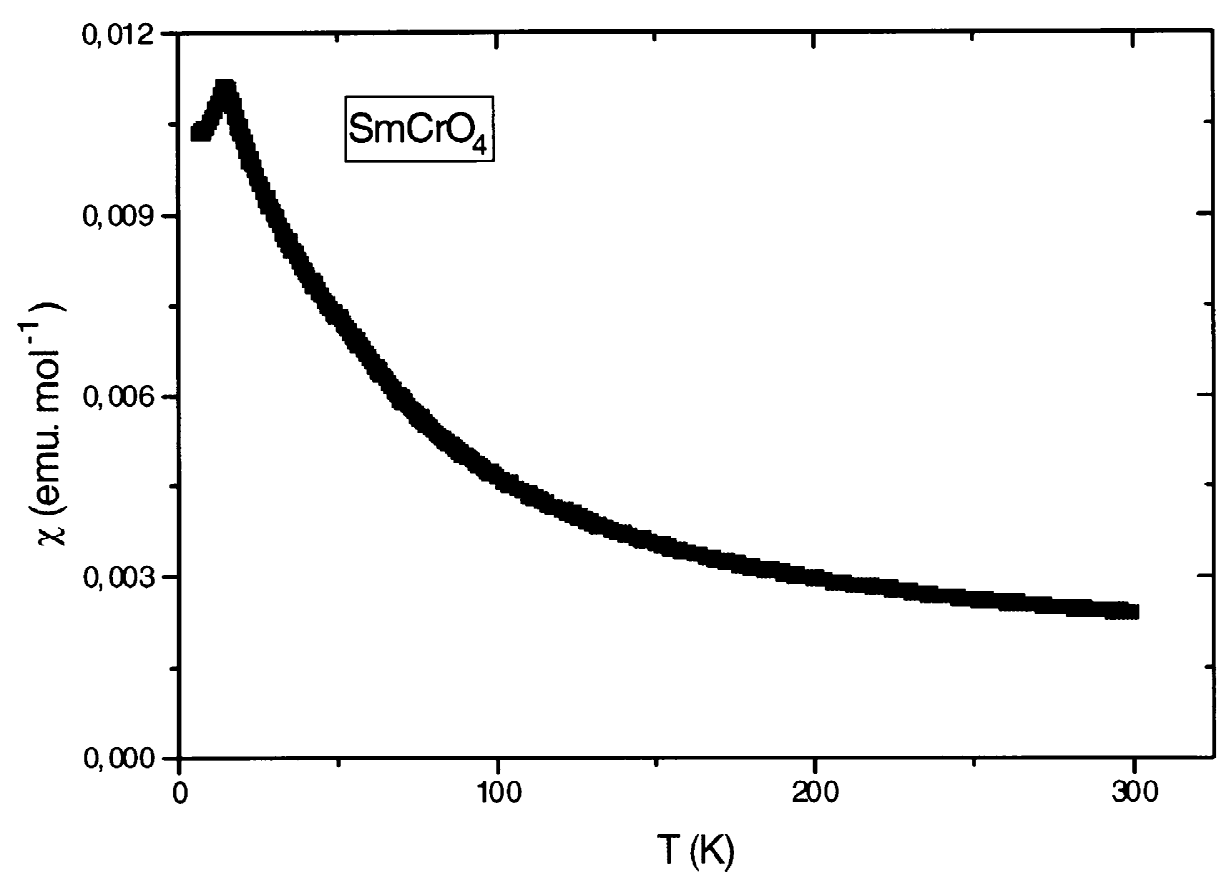

Fig. 6. Variation of the molar magnetic susceptibility with temperature for $\mathrm{SmCrO}_{4}$. 


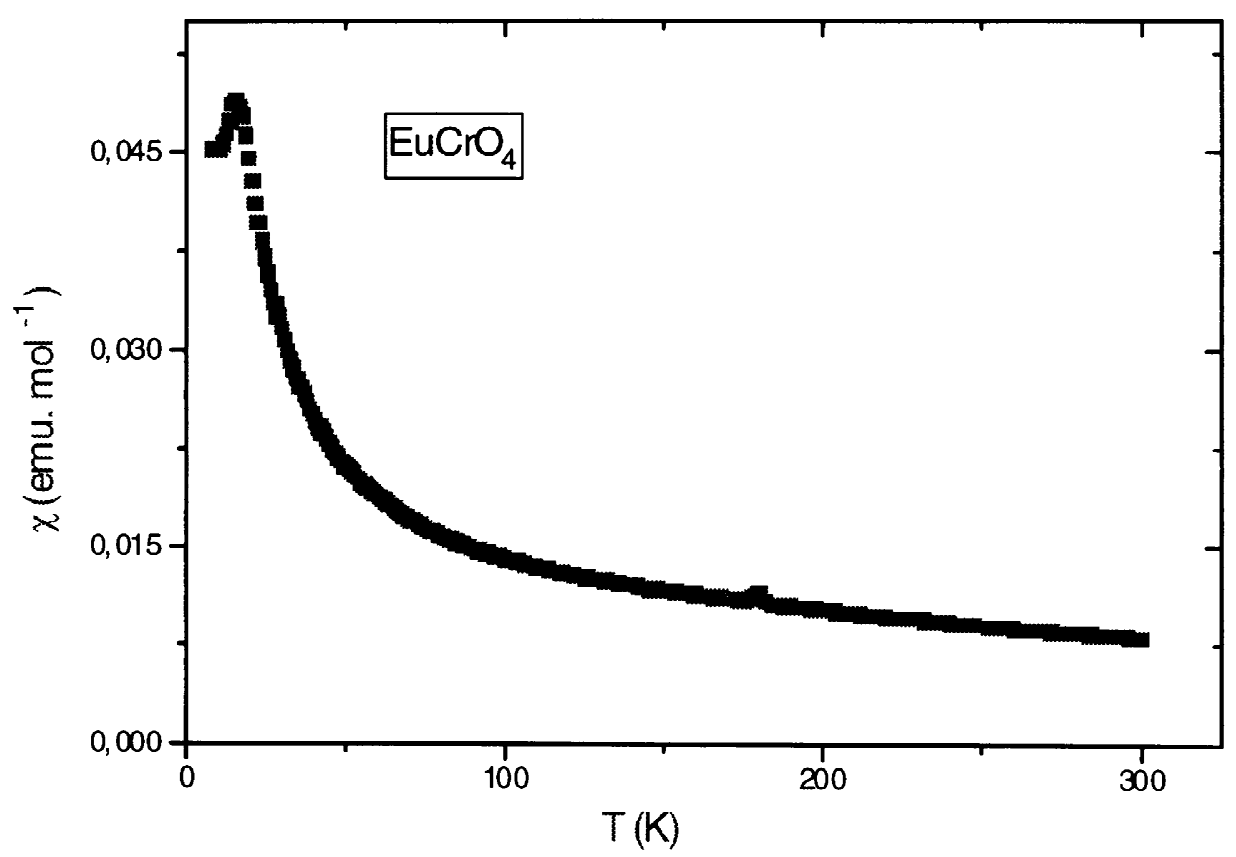

Fig. 7. Variation of the molar magnetic susceptibility with temperature for $\mathrm{EuCrO}_{4}$.

neglected, since, as was mentioned earlier in the case of the isostructural $\mathrm{RXO}_{4}$, where $\mathrm{X}=\mathrm{P}, \mathrm{V}$ and As, they are not operative down to $4.2 \mathrm{~K}$ [21]. The reason for such behaviour is mainly due to the $4 \mathrm{f}$ orbitals being wellshielded by the outer $5 \mathrm{~s}$ and $5 \mathrm{p}$. A more realistic mechanism should involve the $\mathrm{CrO}_{4}$ tetrahedra that connect the $\mathrm{RO}_{8}$ rows, originating two superexchange pathways of the type $\mathrm{R}^{3+}-\mathrm{O}-\mathrm{Cr}^{5+}-\mathrm{O}-\mathrm{R}^{3+}$, as can be observed in Fig. 5 .
The so-called mechanism I implies an intrachain coupling along the $a$-axis, while mechanism II considers interchain interactions between the $\mathrm{RO}_{8}$ bidisphenoids connected via $\mathrm{CrO}_{4}$ tetrahedra, producing a $\mathrm{R}^{3+}-\mathrm{R}^{3+}$ distance of 6.354 (1) $\AA$ in the case of the samarium compound. Since both mechanisms are operative, a three-dimensional character must be proposed for these interactions. Both the relatively large $\mathrm{R}^{3+}-\mathrm{R}^{3+}$ distances obtained in these

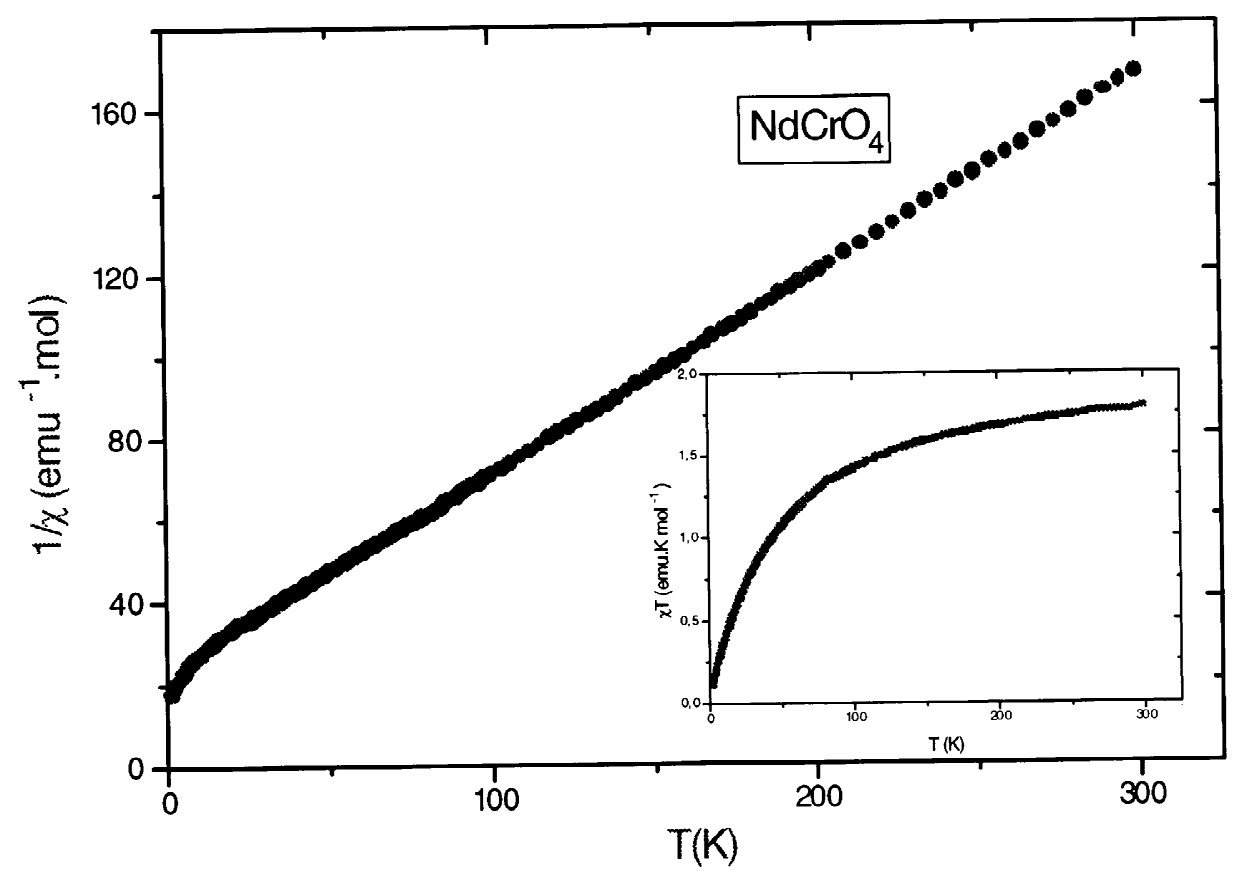

Fig. 8. Temperature dependence of the reciprocal molar susceptibility of $\mathrm{NdCrO}_{4}$. The inset is the $\chi T$ vs. $T$ plot. 
compounds and the superexchange angle, which is very different to $180^{\circ}$, justify the low values of the estimated Néel temperatures, see Table 3.

Neutron diffraction experiments are now in progress, in the case of $\mathrm{LuCrO}_{4}$ and $\mathrm{NdCrO}_{4}$, in order to get a deeper knowledge of the low-temperature magnetic behaviour and to solve the magnetic structure of these oxides.

\section{Acknowledgements}

We thank CICYT for financial support, under Project No. MAT-97-0697-C02-01.

\section{References}

[1] H. Saji, T. Yamadaya, M. Asanuma, J. Phys. Soc. Jpn. 28 (4) (1970) 915.

[2] K. Klein, Int. J. Magn. 5 (1973) 231.

[3] K. Gehring, A.P. Malozemoff, W. Staude, R.N. Tyte, Solid. State. Commun. 9 (1971).

[4] F. Sayetat, Solid. State. Commun. 10 (1972) 379.

[5] J. Sivardiere, Phys. Rev. B8 (1973) 2004.

[6] C.R. Rice, W.R. Robinson, Acta Crystallogr. B32 (1976) 2232.
[7] J.D. Carter, H.U. Anderson, M.G. Shumsky, J. Mater. Sci. 31 (1996) 551.

[8] G. Buisson, F. Bertaut, J. Mareschal, C. R. Acad. Sci. Paris 259 (1964) 411

[9] S.G. Manca, E. Baran, J. Phys. Chem. Solids 42 (1981) 923.

[10] J. Isasi, M.L. Veiga, Y. Laureiro, R. Sáez-Puche, C. Pico, J. Alloys Comps. 177 (1991) 143.

[11] J. Isasi, Thesis, Universidad Complutense, Madrid, Spain, 1994.

[12] J. Isasi, M.L. López, M.L. Veiga, C. Pico, J. Alloys Comps. 232 (1996) 36.

[13] J. Rodriguez-Carvajal, FULLPROF Program II, Grenoble, France, 1993.

[14] L.N. Mulay, E. Boudreaux, in: Theory of Molecular Paramagnetism, Wiley, New York, 1976, p. 494.

[15] H. Schwarz, Z. Anorg. Allg. Chem. 44 (1963) 323.

[16] F. Mabbs, D.J. Machin, Magnetism and Transition Metal Complexes, Chapman and Hall, London, 1973.

[17] J. Van Vleck, The Theory of Electric and Magnetic Susceptibility, Oxford University Press, London, 1965.

[18] H. Walter, H.G. Kahle, K. Mulder, H.C. Schopper, H. Schwarz, Int. J. Magn. 5 (1973) 129.

[19] I. Bueno, O. Garcia, C. Parada, R. Sáez-Puche, J. Less Common. Met. 139 (1988) 261.

[20] M.D. Guo, A.T. Aldred, S.K. Chan, J. Phys. Chem. Solids 48 (3) (1987) 229.

[21] A. Morales-Sanchez, F. Fernández, R. Sáez-Puche, J. Alloys Comps. 161 (1993) 201. 